\title{
ASPECTOS QUÍMICOS E POTENCIAL TERAPÊUTICO DE IMIDAS CÍCLICAS: UMA REVISÃO DA LITERATURA
}

\author{
Valdir Cechinel Filho*, Fátima de Campos e Rogério Corrêa \\ Núcleo de Investigações Químico-Farmacêuticas, Universidade do Vale do Itajaí, CP 360, 88302-202 Itajaí - SC \\ Rosendo A. Yunes e Ricardo J. Nunes \\ Departamento de Química, Universidade Federal de Santa Catarina, CP 476, 88040-900 Florianópolis - SC
}

Recebido em 15/4/02; aceito em 19/7/02

\begin{abstract}
CHEMICAL ASPECTS AND THERAPEUTIC POTENTIAL OF CYCLIC IMIDES: A REVIEW. Cyclic imides consists of an important family of organic compounds with therapeutic potential. In this review, emphasis will be given to the chemical and biological aspects of several sub-classes of this family, incluing maleimides, succinimides, glutarimides, naphtalimides, etc. Additionally, will be focused the contribution of our research group in this field.
\end{abstract}

Keywords: cyclic imides; synthesis; biological activities.

\section{INTRODUÇÃO}

A necessidade do desenvolvimento de novos fármacos, que sejam efetivos contra algumas patologias ainda sem tratamento adequado, e que possam substituir os existentes, porém a custos menores e dotados de menores efeitos adversos, tem impulsionado a comunidade científica a novas e incessantes pesquisas nesta área. A síntese orgânica tem contribuído significativamente neste aspecto, sendo responsável por cerca de $75 \%$ dos fármacos existentes no mercado farmacêutico ${ }^{1,2}$. Cabe ressaltar, porém, que muitos destes fármacos são oriundos de protótipos advindos de produtos naturais, especialmente de plantas, que têm, ao longo dos anos, possibilitado a descoberta de inúmeras moléculas bio-ativas ${ }^{3-6}$.

Muitas classes de compostos orgânicos têm demonstrado promissores efeitos biológicos e a literatura científica relata um crescimento significativo de novas moléculas com potência similar ou superior àquela de um fármaco, sendo que muitos deles encontram-se em estudos pré-clínicos e clínicos avançados e pormenorizados. Entre estas substâncias, pode-se inserir as imidas cíclicas, alvo desta revisão.

As imidas cíclicas são compostos que contém o grupo-CO-N(R)$\mathrm{CO}-$, sendo $\mathrm{R}$ um átomo de hidrogênio, grupo alquila ou grupo arila. Tais compostos podem ser divididos em sub-classes, incluindo as maleimidas, succinimidas, glutarimidas, ftalimidas, naftalimidas, etc., e seus respectivos derivados. Em 1970, Hargreaves e colaboradores $^{7}$ publicaram uma revisão abordando vários aspectos químicos, industriais e biológicos das imidas cíclicas. Nos últimos anos, esta classe de compostos tem ressurgido e atraído a atenção da comunidade científica, devido, principalmente, às suas potencialidades terapêuticas. Como exemplo, podemos citar o caso da talidomida (1) que apesar dos significativos efeitos adversos do passado, ocasionando praticamente $100 \%$ de teratogenicidade, mesmo em doses clí-

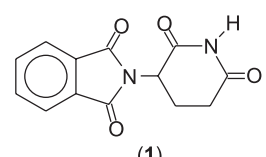

(1) nicas modestas, sendo sua indicação específica para uso na gravi$\mathrm{dez}^{8}$, os recentes estudos têm evidenciado um possível uso desta substância para o tratamento de várias patologias incluindo o câncer ${ }^{9-11}$.

Os departamentos de Química e Farmacologia da UFSC e o Núcleo de Investigações Químico-Farmacêuticas da UNIVALI iniciaram os estudos com esta classe de compostos a partir da descoberta do alcalóide natural filantimida (2), isolado das partes aéreas do Phyllanthus sellowianus ${ }^{12}$. Este composto, derivado da glutarimida, apresentou moderado efeito antimicrobiano ${ }^{13}$, antiespasmódico ${ }^{14}$ e analgésico ${ }^{15,16}$, sendo então usado como modelo ou protótipo para a síntese de inúmeros análogos. Estas imidas cíclicas, análogas à filantimida (2), apresentaram uma variedade de efeitos biológicos, os quais serão abordados no decorrer deste trabalho permitindo, também, a elucidação de vários fatores estruturais relacionados com as respectivas atividades biológicas.<smiles>CNC1CCC(=O)N(CCc2ccccc2)C1=O</smiles>

Desta forma, o presente artigo de revisão enfoca os principais aspectos químicos e biológicos das diferentes sub-classes de imidas cíclicas encontrados na literatura científica, enfatizando ainda os resultados obtidos nos últimos anos em nossos laboratórios.

\section{MÉTODOS SINTÉTICOS GERAIS PARA A OBTENÇÃO DE IMIDAS CÍCLICAS}

São conhecidos vários métodos aplicáveis à preparação da maioria das imidas alifáticas simples ${ }^{7}$. Outros, aplicam-se a imidas aromáticas e cíclicas, nas quais a natureza do sistema anelar conduz a métodos especiais de obtenção ${ }^{7,15}$.

Um dos mais convenientes métodos de obtenção de imidas cíclicas constitui-se no emprego de ácidos dicarboxílicos, como material de partida, com aquecimento a temperaturas que não excedam os $200{ }^{\circ} \mathrm{C}$, na presença de quantidade equimolar de amônia (Esquema 1), ou um composto que possa produzi-la in situ, ou ainda, de derivado substituído da amônia ${ }^{7,15}$. 
Partindo-se do anidrido de ácido, rendimentos satisfatórios podem ser alcançados (60-80\%) na obtenção de imidas cíclicas e seus respectivos derivados $N$-substituídos ${ }^{7,15}$.

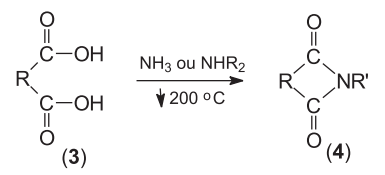

Esquema 1

Outras possibilidades incluem trabalhos que descrevem métodos onde anidridos de ácidos dicarboxílicos, dissolvidos em éter, são tratados com amônia ou amina substituída, obtendo-se, desta forma, o respectivo ácido âmico. $\mathrm{O}$ ácido é então ciclizado na forma imídica através da ação do anidrido acético, a quente, na presença de acetato de sódio anidro. Este método apresenta bons rendimentos e tem sido amplamente utilizado, constituindo-se numa forma mais segura (no que se refere à pureza do produto) de obter imidas cícli$\operatorname{cas}^{13,16,17-22}$. Recentemente, Barn e Morphy ${ }^{23}$ relataram a possibilidade de obtenção de ftalimidas, succinimidas e maleimidas utilizando síntese em fase sólida.

Embora vários métodos sintéticos sejam aplicáveis para a obtenção de imidas cíclicas, algumas sub-classes, como as glutarimidas, maleimidas, succinimidas, etc., possuem suas particularidades e portanto são sintetizadas por diferentes metodologias. No entanto, muitos métodos de síntese, descritos na revisão de Hargreaves e colaboradores ${ }^{7}$, ainda são usados, eventualmente com pequenas modificações, como mudança de alguns reagentes desidratantes ou solventes. Quanto aos aspectos de elucidação estrutural, a utilização de espectroscopia de infravermelho consiste em um método simples e importante para distinguir os sistemas cíclicos (imidas) daqueles de cadeia aberta (ácidos âmicos), analisando-se as diferenças nas bandas de absorção características dos grupamentos carbonila e carboxila $^{7,24}$. Enquanto as imidas apresentam uma banda forte na região de $1700 \mathrm{~cm}^{-1}$ atribuída às carbonilas simétricas, os ácidos apresentam uma banda larga na região de $3000 \mathrm{~cm}^{-1}$ atribuída ao grupo carboxila, e duas bandas intensas dos grupos carbonilas, uma em torno de $1700 \mathrm{~cm}^{-1}(\mathrm{COOH})$ e outra aproximadamente a $1650 \mathrm{~cm}^{-1}$ $(\mathrm{CONH})$. A seguir são mencionadas as principais propriedades químicas e biológicas para as sub-classes de imidas cíclicas.

\section{MALEIMIDAS}

\section{Aspectos químicos}

Embora muitas metodologias tenham sido descritas para a síntese de maleimidas e compostos relacionados, mencionadas na revisão de Hargreaves de $1970^{7}$, o método experimental mais apropriado e versátil para a síntese destes compostos parece ser aquele exemplificado no Esquema 2. O anidrido maleico (5) reage com a amina apropriada (6) para a formação do respectivo ácido maleâmico (7). Este ácido pode ser ciclizado com facilidade através do uso de distintos agentes desidratantes de fácil acesso, como por exemplo, o ácido acético, o acetato de sódio anidro, entre outros, sob aquecimento. Estas reações permitem o uso de diferentes aminas, como as anilinas substituídas, para obter-se derivados maleimídicos $N$-substituídos (8), em bons rendimentos ${ }^{17}$. As tentativas de obtenção das maleimidas diretamente, sem passar pela purificação do ácido âmico, usando $\mathrm{AcOH} / \mathrm{refluxo}$, mostraram-se ineficientes, proporcionando a obtenção dos derivados maleimídicos em baixos rendimentos $(\sim 10 \%)^{25}$.

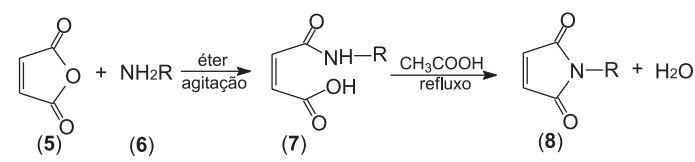

Esquema 2

Nosso grupo de pesquisa tem usado o método em pauta nos últimos anos, obtendo bons resultados quanto aos rendimentos e facilidade de purificação dos compostos supracitados ${ }^{4,15,26}$.

No entanto, novas e importantes abordagens sobre a síntese destes compostos têm sido recentemente descritas. Neste contexto, Faul e colaboradore ${ }^{27}$ desenvolveram um método que permite a obtenção de maleimidas, em uma única etapa, através da condensação de ésteres glioxilatos (9) com acetamidas (10) conforme indicado no Esquema 3. O método é altamente versátil e os produtos geralmente são obtidos com excelentes rendimentos (67-99\%), representando uma alternativa sintética de maior utilidade que os métodos convencionais anteriormente utilizados.

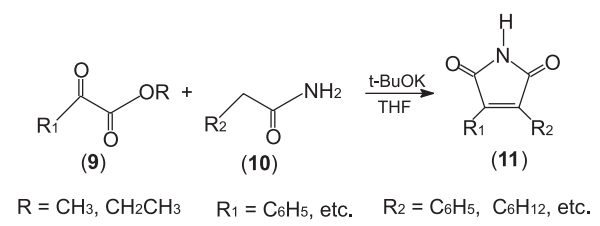

Esquema 3

A $N$-fenilmaleimida (12) e outras maleimidas são substratos para a síntese de derivados com potencial farmacológico ${ }^{15}$. A exemplo, citamos a clorossulfonação da $N$-fenilmaleimida (12), usando $6 \mathrm{~mol}$ de ácido clorossulfônico em aquecimento, levando ao respectivo cloreto de sulfonila (13) com rendimento superior a $80 \%$. Tal composto pode ser usado para a obtenção de diferentes sulfonamidas, através de reações com aminas apropriadas. A ocorrência de uma reação competitiva, como a introdução da amina na dupla ligação imídica, dá-se pela susceptibilidade deste composto à adição nucleofílica $^{25}$. O Esquema 4 ilustra a adição da dimetilamina (14) ao composto (13) e também a substituição nucleofílica no cloro do cloreto de sulfonila formando o composto (15).

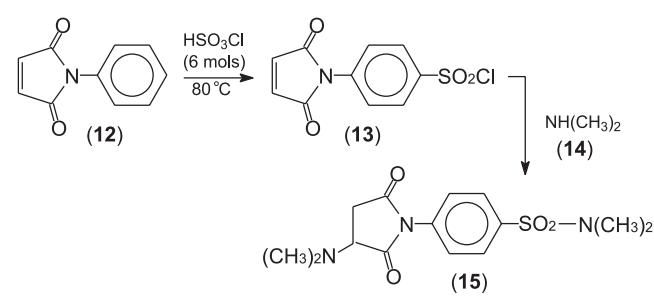

Esquema 4

Estes mesmos autores observaram que o composto (16) pode ser um versátil dienófilo em reações de Diels-Alder de demanda eletrônica "normal", na qual o dienófilo é ativado com grupamentos elétron-retiradores, tal como o grupamento carbonila, entre outros ${ }^{16,28}$. Desta forma, (16) reage com vários dienos, como o ciclopentadieno (17), furano, antraceno, etc., fornecendo os respectivos adutos, conforme indicado no Esquema 5 pela formação do $N$-p-clorosulfonilfenilnorbornenosuccinimida (18).

Beyer e colaboradores ${ }^{29}$ usaram diferentes maleimidas na preparação de derivados de 5-fluoracila (19) e 5'-desoxi-5-fluorouridina 


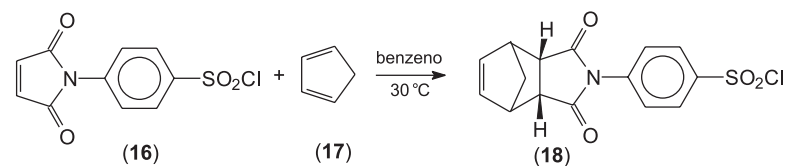

Esquema 5

(28), dois fármacos com propriedades anticâncer, com a finalidade de que o grupo maleimídico atuasse como grupo carreador no sistema biológico. Os Esquemas 6 e 7 mostram as etapas sintéticas realizadas.<smiles>O=C(Cl)c1cccc(N2C(=O)C=CC2=O)c1</smiles>

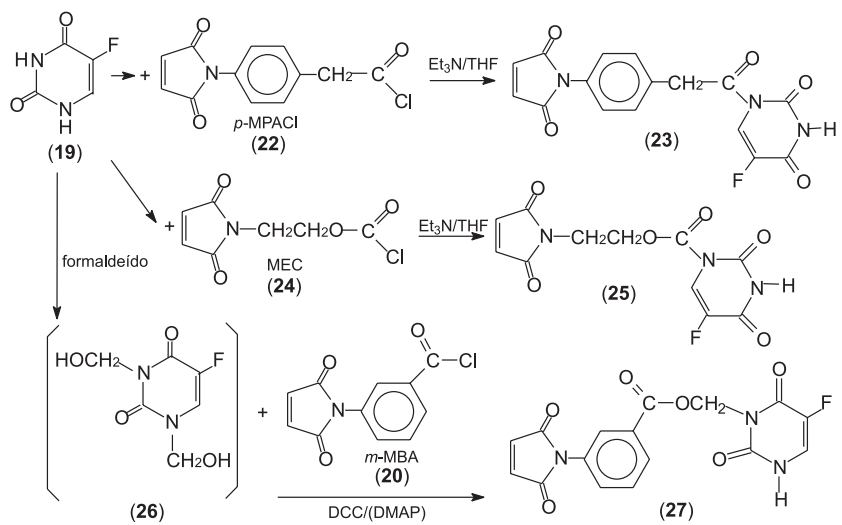

Esquema 6

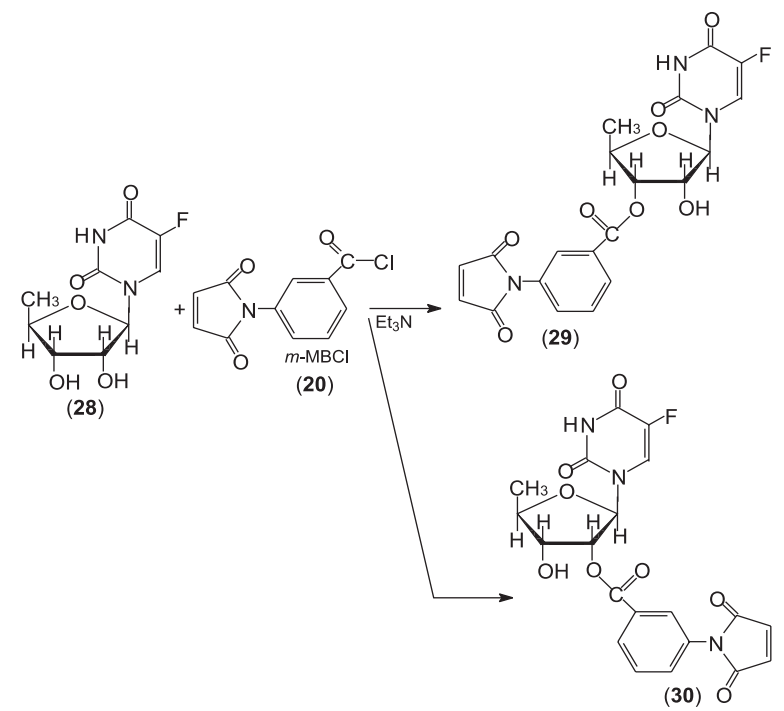

Esquema 7

As maleimidas ocorrem muito raramente na natureza, sendo que o composto 2-etil-3-metil-maleimido- $N$ - $\beta$-D-glucopiranosídeo (31), isolado das folhas de Garcinia mangostana ${ }^{30}$, parece ser um dos poucos exemplos de maleimidas naturais.

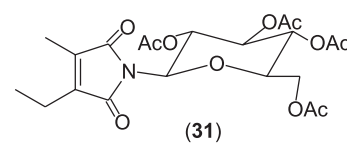

\section{Aspectos biológicos}

Os efeitos biológicos de maleimidas e compostos relacionados vêm sendo estudados há muitos anos. Hargreaves e colaboradores ${ }^{7}$ destacam especialmente os efeitos antifúngico, antibacteriano e inseticida desta classe de compostos. Nunes ${ }^{18}$ verificou que as maleimidas são mais ativas que as succinimidas em relação à atividade antifúngica, sugerindo a importância da dupla ligação imídica na ação biológica. A importância deste fator estrutural foi posteriormente confirmada em estudos desenvolvidos por nosso grupo, os quais serão mencionados a seguir.

Algumas $N$-alquilarilmaleimidas (32) apresentaram atividade contra diferentes bactérias patogênicas aos seres humanos, freqüentemente encontradas em infecções do trato urinário ou intestinal, como Escherichia coli, Staphylococcus aureus, Klebsiella pneumoniae, entre outras ${ }^{13,20}$. Elas também foram ativas contra vários fungos leveduriformes e miceliais, responsáveis por distintas micoses em humanos, como Microsporum canis, Candida albicans, Penicilium, etc. ${ }^{15,31}$ sendo inativos neste trabalho contra Aspergillus flavus. Já as $\mathrm{N}$-alquilarilmaleimidas substituídas (33) apresentaram pouca variação quanto às suas atividades, quando comparadas ao composto não substituído (32), sugerindo principalmente a interferência de fatores estéricos ${ }^{32}$.

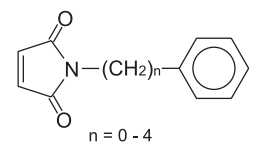

(32)

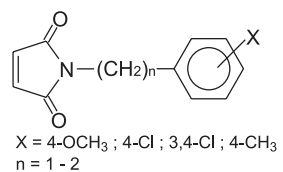

(33)
$N$-arilmaleimidas (34) e $N$-alquilfenil-3,4-dicloromaleimidas (35) foram testadas contra diferentes microorganismos, a fim de avaliar suas atividades antifúngicas, observando-se que alguns compostos apresentaram um efeito inibitório maior que o cetoconazol (36), um antifúngico de amplo espectro utilizado na terapêutica ${ }^{33}$. Os resultados obtidos a partir deste trabalho demonstraram que a introdução de dois átomos de cloro na dupla ligação do anel imídico não aumentou significativamente a atividade antifúngica. Contudo, a distância entre o anel aromático e o anel imídico parece ser um importante fator relacionado à atividade antifúngica destes compostos ${ }^{31}$. Recentemente, estes compostos foram testados contra diferentes fungos patogênicos, comprovando que a atividade dos compostos cresce com o aumento da distância entre o anel imídico e o anel aromático ${ }^{34}$.

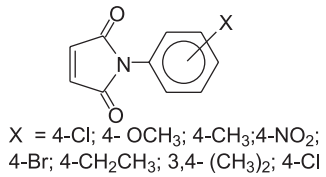

(34)

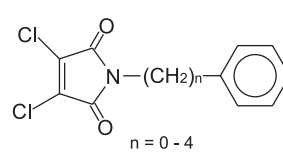

(35)

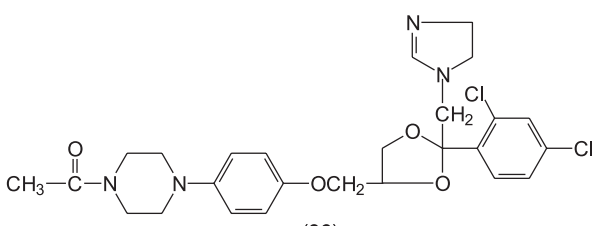

(36) 
Estes compostos apresentaram também uma importante atividade analgésica e antiespasmódica, quando testados em diversos modelos experimentais in vivo e in vitro ${ }^{15,16}$. A introdução de grupos elétrondoadores no anel aromático da $\mathrm{N}$-fenetilmaleimida (37), tais como 4 $\mathrm{OCH}_{3}, 3,4-\left(\mathrm{OCH}_{3}\right)_{2}$ e 4- $\mathrm{CH}_{3}$, aumentou a atividade analgésica. Ao contrário, a introdução de 4- $\mathrm{Cl}$, um átomo elétron-retirador, diminuiu a atividade analgésica, indicando que parâmetros eletrônicos podem estar envolvidos na atividade observada e que grupos elétron-doadores aumentam o efeito. Foi também verificado que a dupla ligação no anel imídico é importante para a atividade, uma vez que succinimidas análogas apresentam somente uma fraca atividade analgésica ${ }^{35}$.

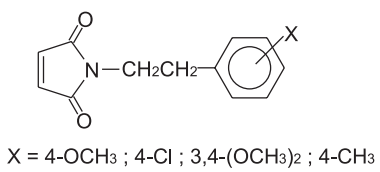

(37)

Substâncias estruturalmente relacionadas às maleimidas, mas contendo o grupo sulfonil na posição 4- do anel aromático foram descritas como potentes analgésicos no modelo de contorções abdominais induzidas pelo ácido acético em camundongos ${ }^{22,26}$.

O composto (38), que possui um átomo de cloro na posição 2 do anel aromático, foi mais ativo que o composto (39), no qual o átomo de cloro está na posição 4 , sugerindo que parâmetros estéricos ou conformacionais estão envolvidos na atividade analgésica ${ }^{36}$.
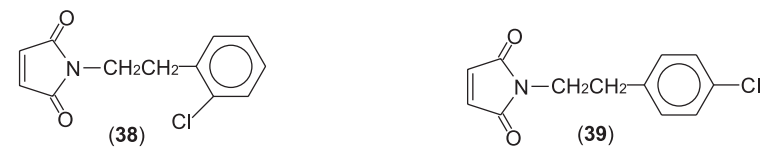

Ainda em relação à atividade analgésica de maleimidas cíclicas, estudos experimentais revelaram que o composto (40), contendo a antipirina ligada diretamente ao anel maleimídico, foi aproximadamente 50 vezes mais ativo que alguns fármacos utilizados na terapêutica $^{36}$. Entretanto, todos os animais foram a óbito após os testes, o que sugere uma alta toxicidade deste composto ${ }^{36}$.

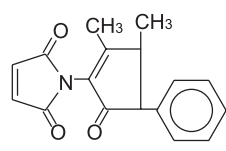

(40)

Recentemente, estudou-se várias outras imidas derivadas da 4aminoantipirina em modelos de avaliação da atividade antinociceptiva. Entre os compostos testados, oito deles apresentaram resultados estatisticamente significativos, em especial a $N$ antipirino-3,4-dicloromaleimida (41), que apresentou uma inibição de $99 \%$ das contorções abdominais induzidas pelo ácido acético em camundongos $(10 \mathrm{mg} / \mathrm{Kg} \text {. i.p. })^{37,38}$.

Em relação aos estudos envolvendo a relação entre a estrutura química e atividade analgésica de 3,4-dicloromaleimidas (42), observou-se que os efeitos estéricos na posição 4 do anel aromático devem ser responsáveis pelo decréscimo da atividade analgésica quan-

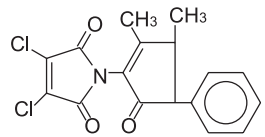

(41)

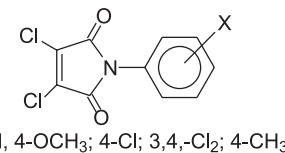

(42)

do há a presença de grupos substituintes na referida posição. Tanto grupos elétron-doadores, quanto elétron-retiradores diminuíram a atividade em relação ao composto não substituído, que foi cerca de 45 a 48 vezes mais potente que alguns fármacos usualmente utilizados na clínica ${ }^{39}$.

As 3,4-dicloroalquilarilmaleimidas (43) e 3-cloro-4-Y-alquilarilmaleimidas (44) foram ativas contra $S$. aureus e E. coli, demonstrando efeitos biológicos promissores, uma vez que todos os compostos (43) foram efetivos contra ambos os microorganismos, alguns deles com resultados ligeiramente menores que os antibióticos tetraciclina (45) e ampicilina (46), utilizados na terapêutica ${ }^{33}$.

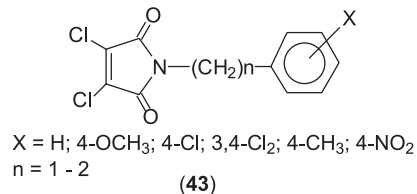

(43)

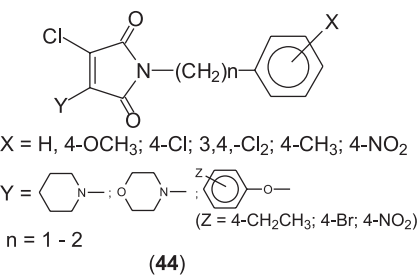

(44)

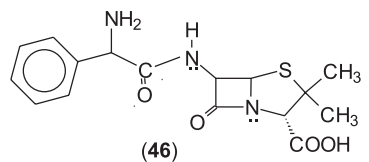

A substituição do átomo de cloro por grupamentos não planares (44), como os anéis piperidínico ou morfolínico, levou a compostos totalmente inativos. Entretanto, a introdução de sistemas rígidos, porém mais planares, como fenóxidos, forneceram compostos que apresentaram ação antibacteriana comparável à apresentada pelas dicloromaleimidas $(\mathbf{4 3})^{40,41}$.

Algumas citraconimidas (47) foram capazes de inibir o crescimento de bactérias patogênicas como E. coli, S. aureus e Salmonela typhimurium. Em geral, a clorosulfonação do anel aromático não afetou significativamente a atividade antibacteriana ${ }^{21}$. Contudo, foi possível observar que os compostos não substituídos e contendo o anel aromático conjugado ao anel imídico $(n=0)$ ou separado por apenas um grupo metileno $(\mathrm{n}=1)$ produziram uma boa atividade, enquanto que os compostos que possuíam dois grupos metileno $(n=2)$ separando o nitrogênio imídico do anel aromático não apresentaram atividade antibacteriana em ensaios de difusão ${ }^{21}$.

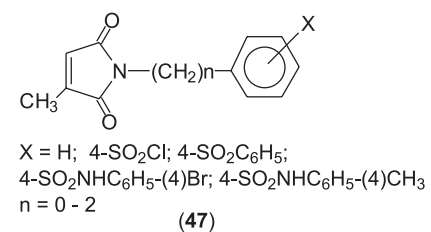

\section{SUCCINIMIDAS}

\section{Aspectos químicos}

A metodologia mais comum utilizada para a síntese de succinimidas (49) consiste em partir de um composto maleimídico, utilizando-se um nucleófilo em uma reação de adição à insaturação olefínica do anel imídico, sendo o benzeno o solvente apropriado e a mistura reacional aquecida por refluxo suave por 30 - 40 min (Esquema 8$)^{15,42,43}$ 


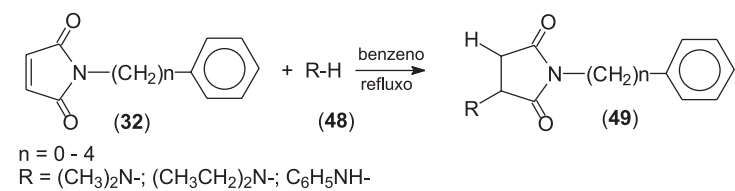

Esquema 8

Lange e colaboradores ${ }^{44}$ prepararam vários derivados da $\mathrm{N}$ hidroxisuccinimida, convertendo o apropriado ácido fenil-succínico (50) ao anidrido (55) com cloreto de acetila (54) e posteriormente tratando o anidrido com a amina desejada, conforme ilustrado no Esquema 9. Alternativamente, a adição da amina apropriada ao ácido fenil-succinimídico (50) também leva à formação de diferentes succinimidas. Este procedimento é bastante versátil, possibilitando a obtenção de inúmeros derivados succinimídicos.

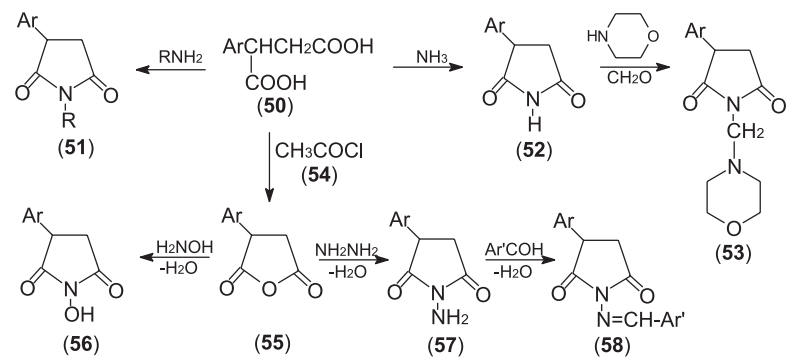

Esquema 9

Cremlyn e colaboradores ${ }^{45}$, usando $N$-fenilmaleimidas clorossulfonadas (13) como material de partida, observaram que a adição de morfolina, piperidina ou pirrolidina em metanol sob temperatura ambiente, à dupla ligação imídica, leva à formação da succinimida desejada $(\mathbf{5 9})$ enquanto que a reação com dimetilamina em excesso (4 mols) em metanol $\left( \pm 50{ }^{\circ} \mathrm{C}\right)$ ocasiona a abertura do anel, obtendo-se o composto (60) (Esquema 10).

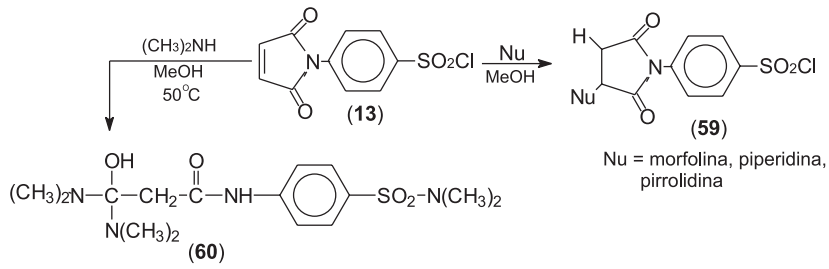

Esquema 10

Ashraf e colaboradores ${ }^{46}$ estudaram os efeitos das radiações de UV (254 nm) sobre algumas succinimidas e observaram que ocorrem fotoreações de diferentes tipos, levando à mistura de derivados.

Recentemente, foi desenvolvida uma nova metodologia para a síntese de derivados amino-succinimídicos, usando a 3,4-dicloro- $N$ fenil-maleimida (61) como material de partida ${ }^{47}$. O produto final (65) é obtido através de uma reação de nitração redutiva e as etapas mostradas no Esquema 11 fornecem bons rendimentos.

Mais recentemente, Obniska e colaboradores ${ }^{48}$ sintetizaram novos derivados pirimidínicos de 3-fenil (68) e 3,3-difenilsuccinimidas (74), com o intuito de avaliar suas propriedades anticonvulsivantes. As rotas sintéticas são indicadas nos Esquemas 12 e 13.

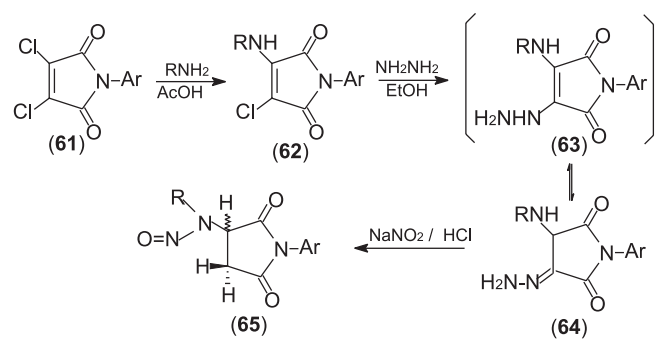

$\mathrm{R}=\mathrm{C}_{6} \mathrm{H}_{5}, 4-\mathrm{Cl}-\mathrm{C}_{6} \mathrm{H}_{4}, 4-\mathrm{CH}_{3}-\mathrm{C}_{6} \mathrm{H}_{4}$, etc...

Esquema 11

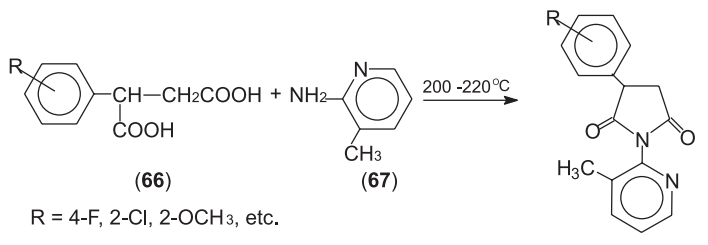

(68)

Esquema 12

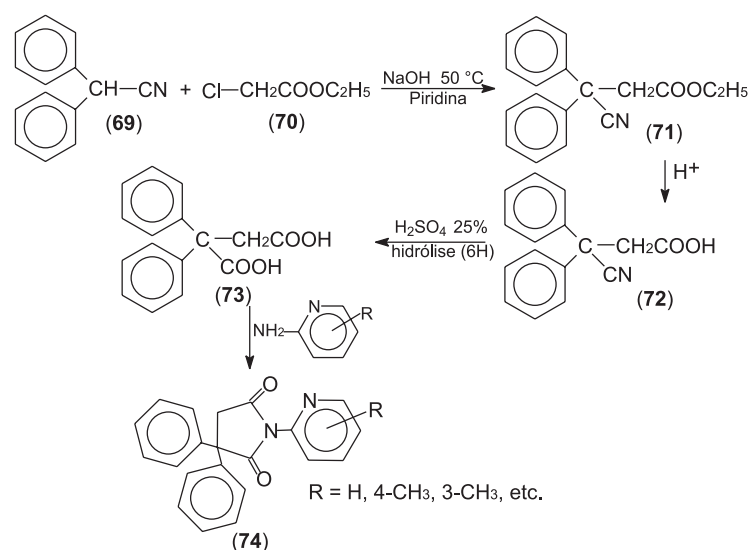

Esquema 13

\section{Aspectos biológicos}

As succinimidas apresentam, em geral, atividade antimicrobiana, antiespasmódica e analgésica inferior àquelas observadas para as correspondentes maleimidas. Tais estudos, conduzidos por nosso grupo de pesquisa, permitiram evidenciar a importância da dupla ligação do anel imídico na atividade biológica, conforme já mencionado.

Do mesmo modo, foi comprovada a ausência de efeitos antifúngicos contra fungos patogênicos para alguns derivados succinimídicos $^{31}$. A importância da dupla ligação imídica na ação biológica foi demonstrada anteriormente por Nunes ${ }^{18}$. Esta hipótese foi também confirmada na ação antiespasmódica e analgésica, onde as succinimidas foram consideravelmente menos ativas que as correspondentes maleimidas ${ }^{20,35,36}$. Por outro lado, a adição do grupo clorossulfonil e sulfonilamidas no anel aromático de $N$-fenilsuccinimidas (75) levou a um aumento no efeito analgésico em camundongos em comparação com as succinimidas não substituídas, sendo, porém, menos ativas que as maleimidas correspondentes ${ }^{22}$.

Os derivados da fenilsuccinimida metasubstituídas (76) e derivados da $N$-aminofenilsuccinimida (77) demonstraram, além de forte ação anticonvulsivante, em convulsões induzidas pelo pentileno- 
tetrazol (78), proteção contra o derrame cerebral induzido por estímulos elétricos ${ }^{44}$. Lange e colaboradores ${ }^{49}$ postularam que a forte ação anticonvulsivante das succinimidas se deve ao fragmento - CONR-CO-, comum também aos barbituratos e outros fármacos reconhecidamente anticonvulsivantes.

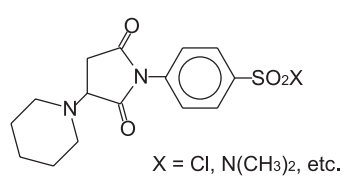

(75)

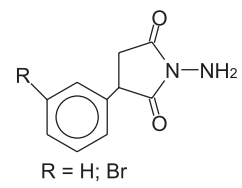

(77)

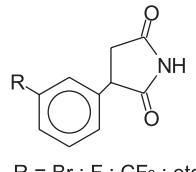

(76)

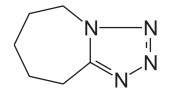

(78)
Outros derivados da succinimida também apresentaram propriedades anticonvulsivantes, similares à da fenitoína (79) e da carbamazepina $(\mathbf{8 0})$, sugerindo que muitas imidas cíclicas atuam potencialmente no sistema nervoso central ${ }^{48,50}$.

O composto 3-fenil-2,3-dimetilsuccinimida (81) e seus derivados $N$-metilados possuem notável atividade anticonvulsivante, particularmente contra convulsões decorrentes de processos epiléticos, sem efeitos hipnóticos colaterais ${ }^{26}$.
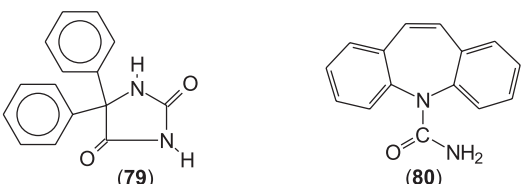

(79)

$(80)$

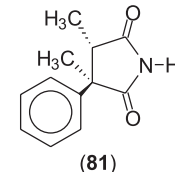

(81)
Em estudos recentes, DiPardo e colaboradores ${ }^{51}$ descobriram uma nova classe de compostos succinimídicos funcionalizados, com perfil antagonista seletivo de receptores adrenérgicos do subtipo $\alpha_{1 \mathrm{~A}}$, com utilidade no tratamento de hiperplasia benigna de próstata.

\section{FTALIMIDAS}

\section{Aspectos químicos}

A ftalimida (84) pode ser preparada a partir do ácido âmico (83), o qual é formado pela agitação em meio etéreo do anidrido ftálico com a amina apropriada (6), na proporção molar 1:1, cujo ácido âmico (83) formado é adicionado ao ácido acético e deixado em refluxo suave por $2 \mathrm{~h}$ (Esquema 14) ${ }^{39}$.

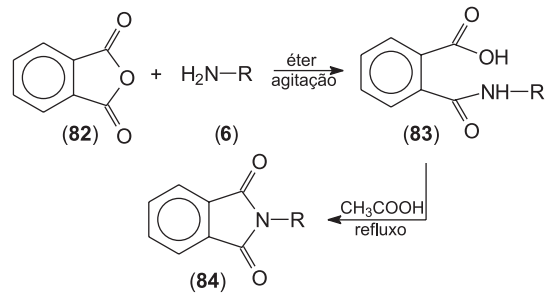

Esquema 14.

Objetivando obter novos fungicidas e pesticidas, Cremlyn e colaboradores ${ }^{24}$ sintetizaram uma variedade de derivados benzenossulfonilados da $\mathrm{N}$-fenilftalimida (85). Foi observado experimentalmente que, dependendo do grupamento $\mathrm{X}$ e das condições (solvente, temperatura), poderia ocorrer a abertura no anel imídico, formando o composto $(\mathbf{8 6})$.

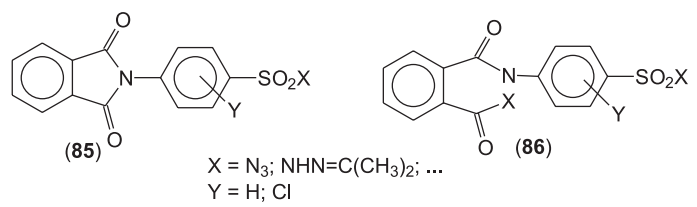

Caswell e colaboradores ${ }^{52}$ investigando reações de substituição nucleofílica ativadas pelo grupo imídico, descobriram que compostos do tipo 4,5-dicloro-ftalimidas (87) podem ser convertidos em compostos do tipo 4-hidroxi-5-nitro-ftalimidas (89) pela ação do nitrito de potássio, conforme ilustrado no Esquema 15.

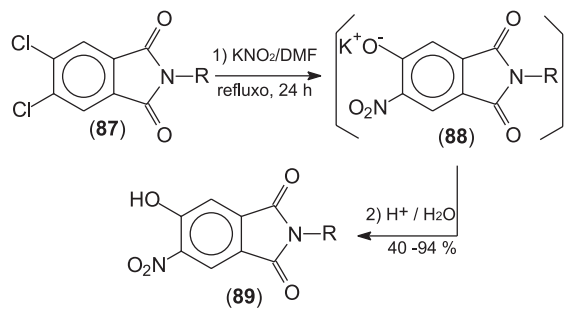

Esquema 15

Visando obter compostos estruturalmente relacionados à talidomida (1) para posterior avaliação da atividade anticonvulsivante dos análogos obtidos, Poupaert e colaboradores ${ }^{53}$ sintetizaram inúmeros compostos (92). Para tanto, foi usado o anidrido ftálico (90) como substrato na presença de amina apropriada (91), em ácido acético sob refluxo, ocorrendo a ciclização direta do anel imídico em uma única etapa (Esquema 16) ${ }^{54}$.

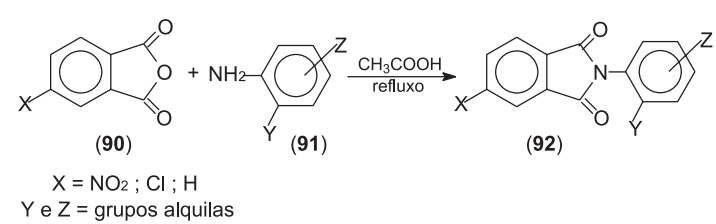

Esquema 16

Bogdal e colaboradores ${ }^{55}$ elaboraram um novo método para sintetizar $N$-alquilftalimidas (84) via alquilação da ftalimida (93) na ausência de solvente sob irradiação por microondas. As reações foram realizadas misturando a ftalimida (93) com haleto de alquila (94) adsorvido em carbonato de potássio. Os produtos foram obtidos com bons rendimentos (49-95\%) em tempo reduzido (4-10 min) (Esquema 17) ${ }^{54}$.

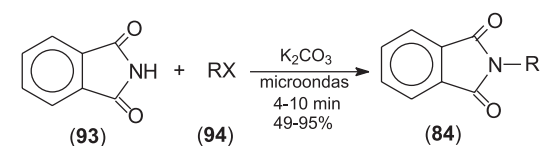

Esquema 17

Recentemente, Antunes e colaboradores ${ }^{56}$ também relataram o uso de um forno microondas para obter um derivado da ftalimida (96), o qual foi diretamente preparado com bom rendimento (60\%), conforme ilustra o esquema (Esquema 18). 


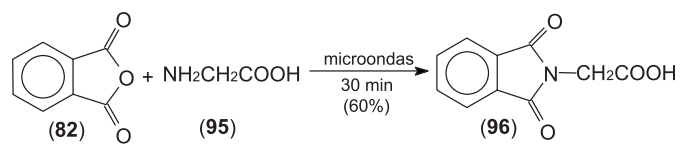

\section{Esquema 18}

Kamal e colaboradores ${ }^{57}$ estudaram novas possibilidades para a síntese de ftalimidas $N$-substituídas e tiveram grande êxito reagindo anidrido ftálico (82) e azidas apropriadas (97) em presença de iodotrimetilsilano, formado in situ, obtendo-se as $N$-fenilftalimidas substituídas (98) em excelentes rendimentos após poucos minutos de reação (Esquema 19).

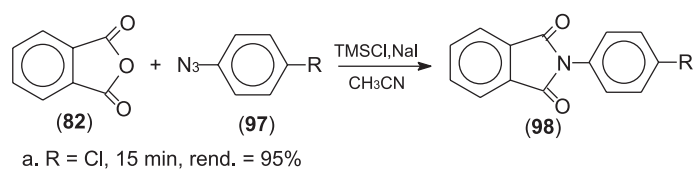

a. $\mathrm{R}=\mathrm{Cl}, 15 \mathrm{~min}$, rend. $=95 \%$

b. $\mathrm{R}=\mathrm{OCH}_{3}, 15 \mathrm{~min}$, rend. $=95 \%$

\section{Esquema 19}

\section{Aspectos biológicos}

Algumas ftalimidas cíclicas provenientes de alquil éteres, tioéteres, sulfóxidos e sulfonas, em doses de 10 e $20 \mathrm{mg} / \mathrm{Kg}$, exerceram atividade hipolipidêmica em $\operatorname{ratos}^{58-60}$. Derivados cíclicos $N$-substituídos da ftalimida, particularmente os compostos 2,3-diidroalazina1,4-diona (99) e difenimida (100) reduziram os níveis séricos de ácido úrico em camundongos normais e hiperúricos tratados com doses de $20 \mathrm{mg} / \mathrm{Kg} /$ dia, i.p., durante 14 dias $^{61}$. A atuação potencial das imidas cíclicas no sistema nervoso central foi comprovada pela atividade de diversos derivados da $N$-fenilftalimida (102), especialmente o composto (101), com atividades anticonvulsivantes similares às da fenitoína (79) e da carbamazepina $(\mathbf{8 0}){ }^{50,53}$.<smiles>[R]C=CCOc1nn([R])c(=O)c2ccccc12</smiles>
(99)<smiles>Cc1cccc(C)c1N1C(=O)c2ccc(N)cc2C1=O</smiles>
(101)

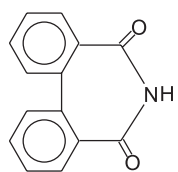

(100)

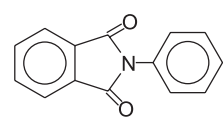

(102)
A $N$-fenilftalimida (102) e compostos relacionados apresentaram atividade antibacteriana contra bactérias patogênicas, porém o efeito foi menos pronunciado quando comparado com os derivados da maleimida e 3,4-dicloromaleimida ${ }^{15,39}$.

A talidomida (1), que possui uma estrutura molecular derivada da ftalimida, porém também contendo um anel glutarimídico, pode ser considerada a molécula mais relevante pertencente a esta classe de compostos. Como mencionado anteriormente, apesar dos efeitos adversos no passado ocasionando má formação congênita, nos últimos anos, a talidomida tem sido tema de estudos de diversos grupos de pesquisa ${ }^{11,62-64}$.

Singal e colaboradores ${ }^{9}$ indicaram que o composto (1) pode representar uma grande esperança para indivíduos com câncer, uma vez que tem se mostrado muito ativo contra o mieloma avançado, inclusive em pacientes com mieloma múltiplo.
Mais recentemente, Ribeiro e colaboradores ${ }^{65}$ demonstraram que a talidomida (1) apresenta potente efeito analgésico em vários modelos de dor, cujo mecanismo parece estar associado à inibição da produção do fator de necrose tumoral alfa (FNT- $\alpha$ ) sem, no entanto, possuir ação sobre o SNC.

Além das propriedades citadas, muitos outros efeitos benéficos relevantes e promissores têm sido relatados para a talidomida, tornando-a uma molécula - líder para o futuro desenvolvimento de novos fármacos ${ }^{11,62-64}$.

Komoda e colaboradores ${ }^{66}$ demonstraram que alguns derivados ftalimídicos apresentam perfil inibidor de aminopeptidases, alguns deles, como o PIQ-22 (103) com potencial anticâncer, inibindo o processo de metástase tumoral.

Estudos recentes confirmaram os efeitos analgésicos de derivados da ftalimida, especialmente o composto (104) o qual foi cerca de 50 vezes mais potente que a aspirina no modelo de nocicepção induzida por ácido acético, em camundongos, atuando ainda na segunda fase (dor de origem inflamatória) do teste da formalina ${ }^{56}$.

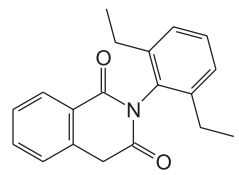

(103)<smiles></smiles>

(104)

\section{NAFTALIMIDAS}

\section{Aspectos químicos}

Os compostos são geralmente preparados de maneira simples, pela adição da amina apropriada (6) $(1 \mathrm{~mol})$ para cada mol de anidrido (105), sob refluxo com ácido acético. O produto (107) pode ser purificado por recristalização com etanol (Esquema 20$)^{40}$.

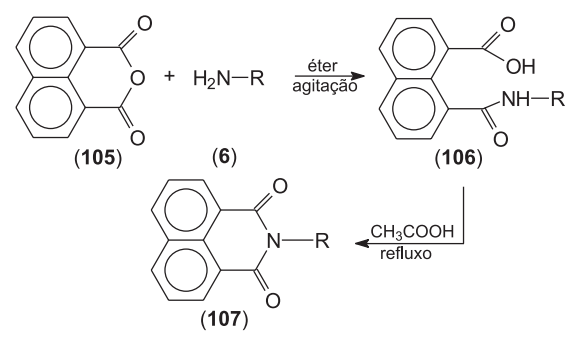

Esquema 20

Investigando novas substâncias com possível uso como corante para material polimérico, Konstantinova e colaboradores ${ }^{67,68}$ sintetizaram alguns 4-amino derivados da 1,8-naftalimida, contendo um grupo insaturado para copolimerização (109). A rota sintética está indicada no Esquema 21 e os compostos foram obtidos com rendimentos superior a $90 \%$.

Posteriormente, diante do êxito nos trabalhos anteriores, os mesmos autores exploraram sinteticamente o composto (109), obtendo novos derivados (110) para uso como brilho fluorescente e corante (Esquema 21) ${ }^{69,70}$.

\section{Aspectos biológicos}

Algumas naftalimidas possuem atividade citostática, sendo utilizadas na oncologia. Muitos destes compostos tiveram tal atividade avaliada e já são utilizados na terapêutica. Um exemplo característi- 


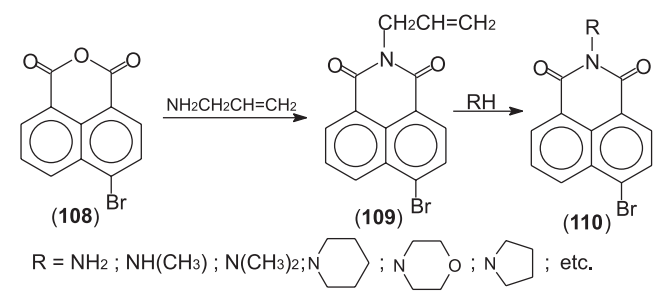

Esquema 21

co é a mitonafida ( $N$-[2-(dimetilamino)etil]-3-nitronaftalimida) (111), a qual apresentou atividade citostática contra diversos tipos de tumores $^{71,72}$. A amonafida ( $N$-[2-(dimetilamino)etil]-3-aminonaftalimida) (112) foi utilizada em estudos contra tumores malignos, exercendo atividade em adenocarcinoma de mama e próstata, não sendo, porém, efetiva em células do pulmão e do colo de útero ${ }^{72}$. Por outro lado, algumas imidas cíclicas têm apresentado efeito teratogênico em roedores ${ }^{73}$.

Outros compostos relacionados à mitonafida (111) e amonafida (112) são fortes candidatos ao desenvolvimento de estudos clínicos para obtenção de novos fármacos. Um exemplo é o derivado da amonafida (112), o composto (113) que demonstrou uma pronunciada atividade anti-leucêmica in vivo ${ }^{74}$.

Novas $\mathrm{N}$-arilnaftalimidas (114) e bis- $\mathrm{N}$-arilnaftalimidas (115) foram avaliadas quanto aos seus efeitos analgésicos, no modelo de contorções abdominais em camundongos (10 mg/kg, i.p.), apresentando uma inibição de aproximadamente $90 \%$ das contorções, não havendo diferenças significativas entre os análogos. Observou-se ainda a importância de grupos substituintes elétron-doadores (como metila e metoxila) no aumento da atividade analgésica. Alguns destes compostos mostraram-se muito mais ativos que o ácido acetil salicílico e o acetaminofeno ${ }^{75,76}$.<smiles>CN(C)CCN1C(=O)c2cccc3cc([N+](=O)[O-])cc(c23)C1=O</smiles><smiles>CN(C)CCN1C(=O)c2cccc3cc(N)cc(c23)C1=O</smiles><smiles>CCN(CC)CCN1C(=O)c2cccc3cc(N)cc(c23)C1=O</smiles>

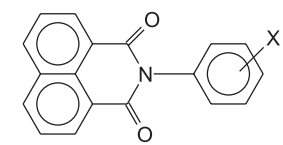

$\mathrm{X}=\mathrm{H} ; 4-\mathrm{CH}_{3} ; 4-\mathrm{OCH}_{3} ; 4-\mathrm{Cl} ; 3,4-\mathrm{Cl}$ (114)

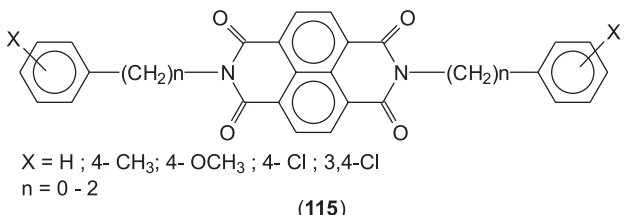

\section{GLUTARIMIDAS}

\section{Aspectos químicos}

Em 1988, foi isolado e identificado um novo alcalóide da fração alcaloídica ativa da planta Phyllanthus sellowianus ${ }^{14}$. O composto é derivado da glutarimida, sendo denominado filantimida $(2)^{12}$. A descoberta deste alcalóide foi o ponto de partida para nosso grupo de pesquisa iniciar os estudos de síntese e atividade biológica de imidas cíclicas. Neste contexto, cabe mencionar que muitos compostos análogos da filantimida (2) foram sintetizados e estudados sob os aspectos biológicos, obtendo-se várias imidas cíclicas e compostos de estruturas moleculares semelhantes, que demonstraram relevantes ações antibacterianas, fungicidas, antiespasmódicas e analgésicas ${ }^{15,77}$, cujos resultados estão sendo enfatizados no decorrer deste trabalho.

Em 1971, Dounchis e Volpp ${ }^{78}$ descreveram a síntese de vários análogos do agente antifúngico e antibacteriano streptimidona (116), isolado de fungos. Os autores prepararam vários compostos, especialmente derivados do tiofeno (117) e da acetofenona (118).

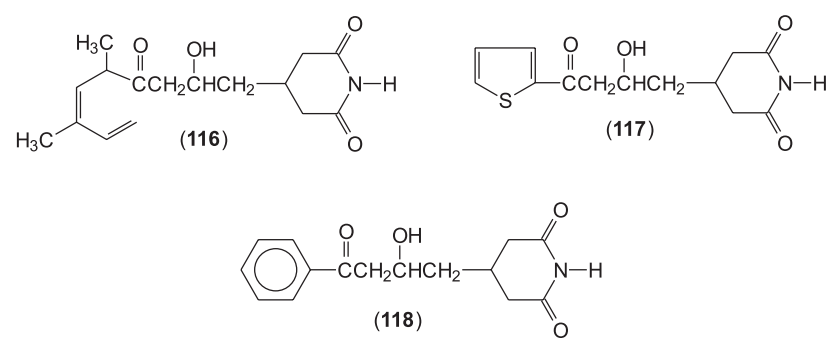

De e $\mathrm{Pal}^{79}$ prepararam novos derivados da glutarimida com estrutura relacionada à talidomida (1). Para tanto, o ácido 3fenilglutárico (119) foi convertido no anidrido-3-fenilglutárico (120) pela ação do anidrido acético e subseqüentemente tratado com amônia e várias outras aminas, para obter as imidas correspondentes (121) (Esquema 22).

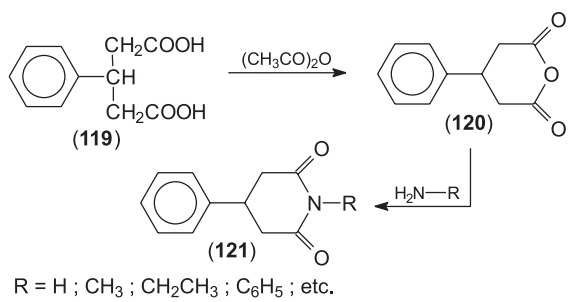

Esquema 22

A ciclização dos derivados da glutarimida necessita de condições especiais, como o uso de um forte agente desidratante, como por exemplo o cloreto de acetila. Ao contrário, as maleimidas podem ser ciclizadas em condições experimentais mais suaves, usando o ácido acético como agente desidratante. Isto se verifica devido aos correspondentes ácidos maleâmicos, que possuem uma ligação dupla no anel imídico, proporcionarem uma configuração planar à molécula. Por outro lado, os ácidos glutarâmicos, que possuem um anel imídico de 6 membros, estão mais tensionados, dificultando a ciclização ${ }^{80-82}$.

Uma série de derivados da glutarimida contendo dois grupos ciano em posição 3 e 5 (122) do anel imídico foi sintetizada por Patel e colaboradores $^{83}$, no intuito de encontrar novos compostos com potencial farmacológico, especialmente efeitos analgésicos, antitérmicos e anticonvulsivantes. Porém, os estudos demonstraram que os compostos são destituídos destas ações farmacológicas, alguns deles exercendo efeitos tóxicos.

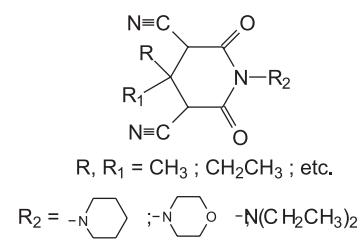

(122) 
Goehring e colaboradores ${ }^{84}$ desenvolveram uma importante e versátil rota sintética para a obtenção de 2-benzil-glutarimidas (126), partindo da glutarimida (123), formando o respectivo sal da amida (124) e adicionando eletrófilos (125) apropriados, como haletos de alquila, aldeídos, cetonas, etc. (Esquema 23).

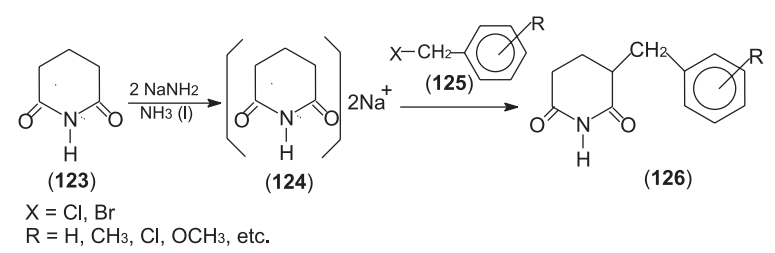

Esquema 23

Os compostos $N$-alquilarilglutarimidas (130) podem ser obtidos através da reação do anidrido glutárico (127) com anilina ou anilinas substituídas (128) em éter, resultando nos respectivos ácidos âmicos substituídos (130). Estes são facilmente isolados do meio reacional por filtração ou extração. Posteriormente, utiliza-se para ciclização uma mistura de ácido acético e cloreto de acetila 1:2 (refluxo por 2 h), como agentes desidratantes, para a obtenção das respectivas $N$ aril-glutarimidas (129) (Esquema 24) ${ }^{82}$.

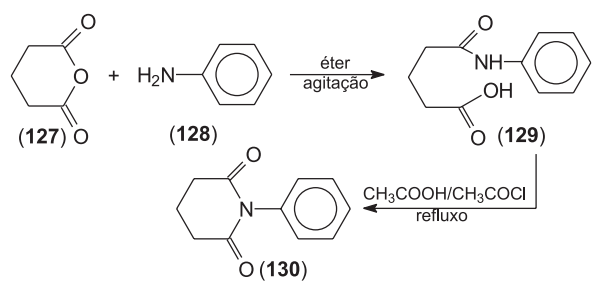

Esquema 24

Estes compostos podem ser geralmente isolados do meio reacional através de precipitação em banho de água-gelo e/ou extraídos primeiramente com clorofórmio e, em seguida, com uma solução 5\% de bicarbonato de sódio, para neutralizar o ácido em excesso ${ }^{82}$.

Recentemente, um novo alcalóide derivado da glutarimida foi isolado das raízes de Croton membranaceus, o qual foi denominado julacrotina (131) e possui uma estrutura molecular similar à filantimida ${ }^{85}$.

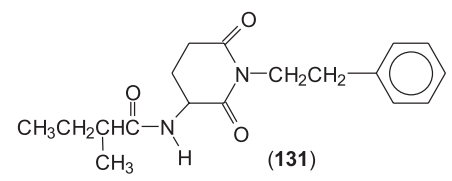

\section{Aspectos biológicos}

Vários compostos derivados da glutarimida, especialmente aqueles substituídos na posição $\beta$ do anel imídico, apresentaram atividade antifúngica contra diferentes fungos patogênicos, como os compostos (117), (118), (132) e $(\mathbf{1 3 3})^{78}$.
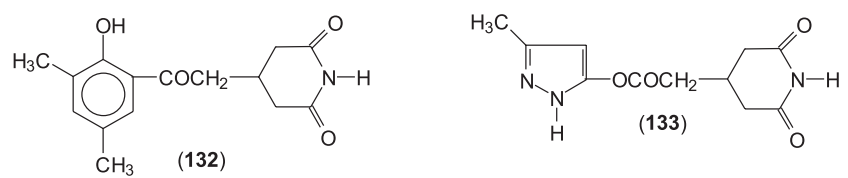

Alguns derivados da glutarimida, particularmente aqueles substituídos na posição 3 pelo grupo fenila e na posição 6 , por diferentes grupos alquila, (134) demonstraram atividade antitumoral em camundongos ${ }^{79}$.

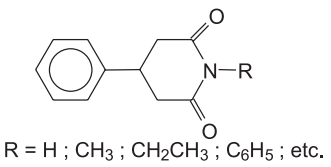

(134)

As glutarimidas pertencem a um grupo de compostos com várias ações sobre o sistema nervoso central, causando desde depressões à convulsões. Uma pequena alteração na molécula da glutarimida pode fazê-la atuar como agente convulsivo ou depressivo ${ }^{86}$.

Algumas glutarimidas mostraram-se equipotentes e mais seletivas que o diazepan, entre outros fármacos, como é o caso da buspirona $(\mathbf{1 3 5})^{87}$. Estes compostos têm sido investigados quanto às suas características antipsicóticas, acreditando-se que as afinidades aos receptores de dopamina, bem como a habilidade de bloquear a catalepsia, sejam dependentes das características eletrônicas e lipofílicas dos substituintes empregados. Um exemplo desta nova classe de fármacos antipsicóticos é a tiospirona (136), já utilizada na terapêutica, tendo demonstrado reduzidos efeitos colaterais e forte efeito antagonista serotoninérgico ${ }^{88}$.
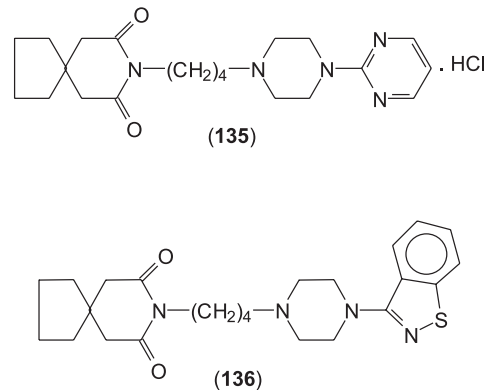

Como a buspirona (135) está inserida entre os fármacos mais utilizados no tratamento de doenças mentais, demonstrando uma forte atividade ansiolítica, alguns análogos, como as 5,7-dioxabiciclo [2,2,2] octano-2,3-dicarboximida substituída (137), foram obtidos a partir de uma cicloadição de Diels-Alder, envolvendo a hidroquinona e o anidrido maleico. Estas imidas cíclicas $N$-substituídas apresentaram atividade sobre o sistema nervoso central, como a esperada atividade ansiolítica ${ }^{89}$.

Recentemente, Kassakowski e Jarocka ${ }^{90}$ sintetizaram novas imidas cíclicas análogas à tiospirona (137), e observaram que alguns dos compostos apresentam promissores efeitos ansiolíticos, atuando por mecanismo de ação semelhante à buspirona (135).

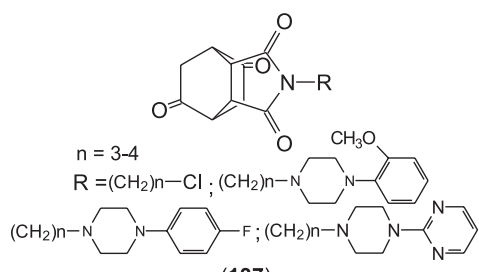

(137)

Patel e colaboradores ${ }^{83}$ investigaram distintas propriedades farmacológicas dos derivados da glutarimida contendo 2 grupos ciano, indicados anteriormente (130), observando que alguns compostos 
induzem depressão hipnótica. Porém, são praticamente destituídos de efeitos anticonvulsivantes, analgésicos e antipiréticos quando analisados em modelos convencionais, em ratos e camundongos ${ }^{83} \mathrm{em}$ doses inferiores a $32 \mathrm{mg} / \mathrm{Kg}$, via administração i.p.

Goehring e colaboradores ${ }^{84}$ estudaram uma série de 2 benzilglutarimidas e seus $N$-metil análogos (138), observando que alguns compostos apresentaram promissores efeitos anticonvulsivantes em ratos e camundongos. O composto (139) foi o mais potente testado, emergindo como um candidato a um novo protótipo de fármaco, sendo mais potente que alguns fármacos usados na clínica e destituído de efeito tóxico ${ }^{84}$.
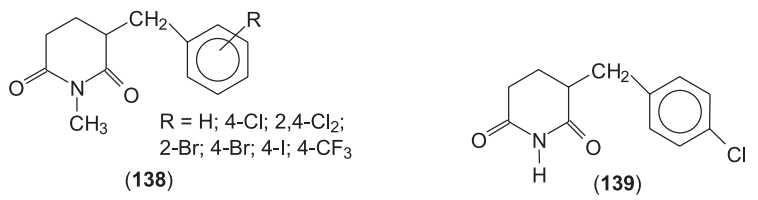

O composto 2,2-dimetil- $N$-fenetil-glutarimida (140) e seu respectivo ácido âmico (141) apresentaram promissor efeito analgésico ao inibir as contorções abdominais causadas pelo ácido acético em camundongos ${ }^{15}$. O composto (140) causou uma discreta atividade analgésica, inibindo $31 \%$ das contorções abdominais $(30 \mathrm{mg} / \mathrm{kg})$, enquanto o composto (141) apresentou uma $\mathrm{DI}_{50}$ de $11 \mu \mathrm{mol} / \mathrm{kg}$, sendo cerca de 12 vezes mais potente que alguns fármacos utilizados na terapêutica, como os analgésicos ácido acetil salicílico e $\operatorname{acetaminofeno}^{15,36}$.
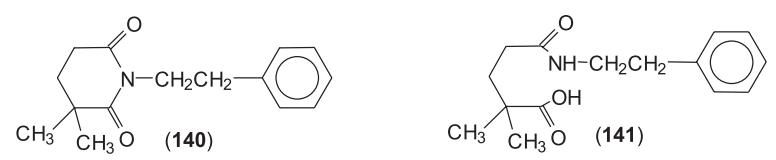

Mais recentemente, confirmou-se que a $N$-fenilglutarimida (130) e seu respectivo ácido âmico (129) também foram efetivos como analgésicos, tanto no modelo de dor induzida pelo ácido acético, como no modelo de formalina, ambos em camundongos ${ }^{82}$. Foi verificado que a maioria dos compostos testados são mais eficazes que o ácido acetil salicílico, acetaminofeno e indometacina ${ }^{82}$.

Estudos recentes têm demonstrado que o grupo glutarimídico substituído em posição $\alpha$ ou $\beta$ no anel, age como uma molécula carreadora, transportando biologicamente os substituintes ativos através das membranas celulares ${ }^{91}$.

\section{OUTRAS IMIDAS CÍCLICAS}

\section{Aspectos químicos e biológicos}

Além das sub-classes de imidas cíclicas mencionadas anteriormente, outras têm sido estudadas em menor grau, e alguns exemplos são apresentados a seguir.

Fujinami e colaboradores ${ }^{92}$ investigaram o potencial antifúngico de várias substâncias (oxazolidinas) estruturalmente relacionadas à succinimida, especialmente contra o fungo Sclerotinia sclerotiorum.

Os compostos foram obtidos pela rota sintética indicada no Esquema 25 e alguns deles demonstraram interessante perfil antifúngico.

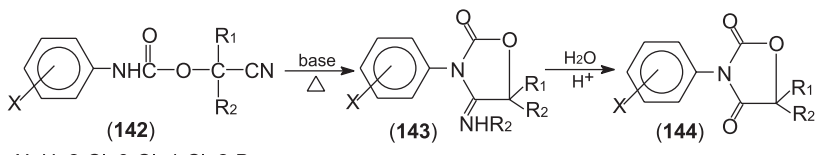

$\mathrm{X}=\mathrm{H}, 2-\mathrm{Cl}, 3-\mathrm{Cl}, 4-\mathrm{Cl}, 2-\mathrm{Br}, \ldots$ $\mathrm{R}_{1}=\mathrm{R}_{2}=\mathrm{H}, \mathrm{CH}_{3}$
Aboul-Enein ${ }^{93}$ obteve uma nova glutaconimida (146) em excelente rendimento (96\%) a partir da glutarimida (145), usando bicarbonato de sódio e dimetil sulfóxido a $80^{\circ} \mathrm{C}$ por $1 \mathrm{~h}$, conforme ilustrado no Esquema 26.

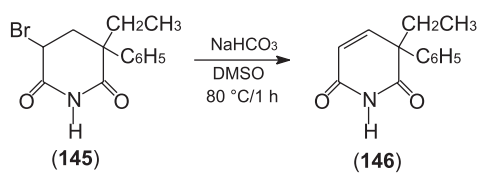

Esquema 26

Buscando obter novos fármacos similares à tiospirona (136), New e colaboradores ${ }^{94}$ sintetizaram vários análogos contendo heteroátomos inseridos no anel imídico. Entre os vários compostos analisados como possíveis agentes antipsicóticos, o composto (147) foi o que apresentou os melhores resultados, demonstrando um mecanismo de ação seletivo e poucos efeitos colaterais, sendo um forte candidato a novo protótipo de fármaco.

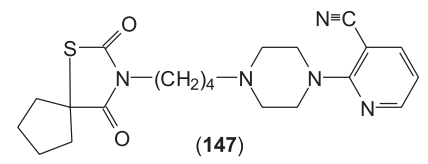

Pesquisadores poloneses têm focado a atenção para a descoberta de compostos que atuem sobre o sistema nervoso central e constataram que várias carboximidas atuam como antipsicóticos e ansiolíticos, alguns deles possuindo afinidades pelo receptor $5-\mathrm{HT}_{1 \mathrm{~A}}{ }^{89,95,96}$. Tais compostos foram obtidos usando as rotas indicadas nos Esquemas 27 e 28.

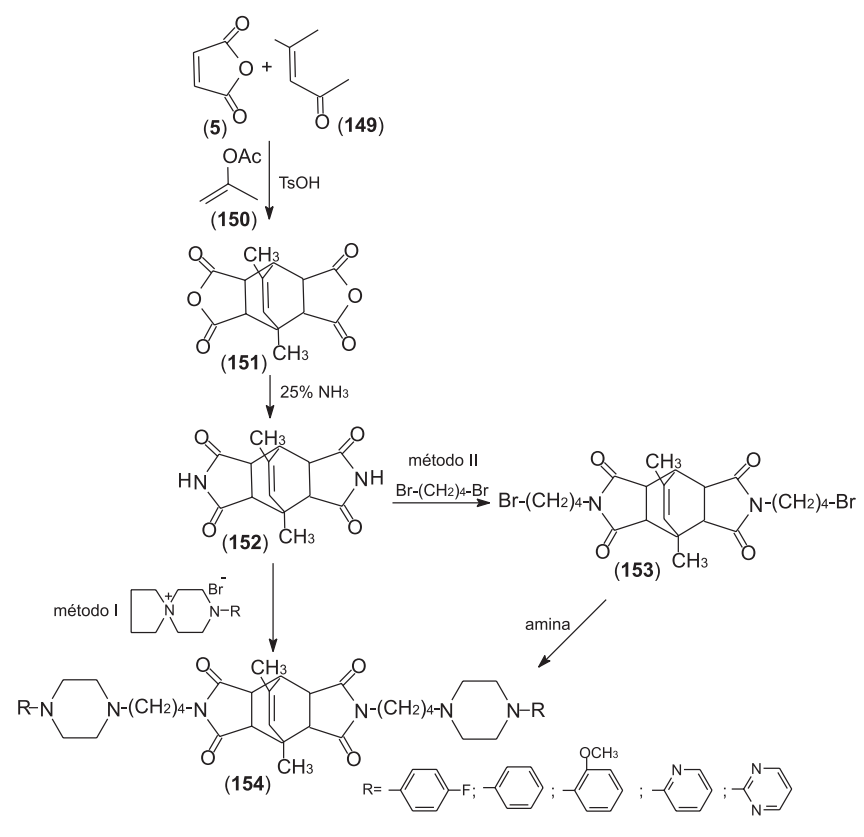

Esquema 27

Poucos estudos relativos à toxicidade de imidas cíclicas foram relatados na literatura. Um dos raros estudos demonstrou que o derivado da ftalimida (158) e uma difenamida (159) não apresentaram propriedades tóxicas comprometedoras em roedores e tampouco atuaram sobre a fertilidade destes aminais ${ }^{73}$.

Os protótipos a fármacos poliméricos têm recebido muita aten- 


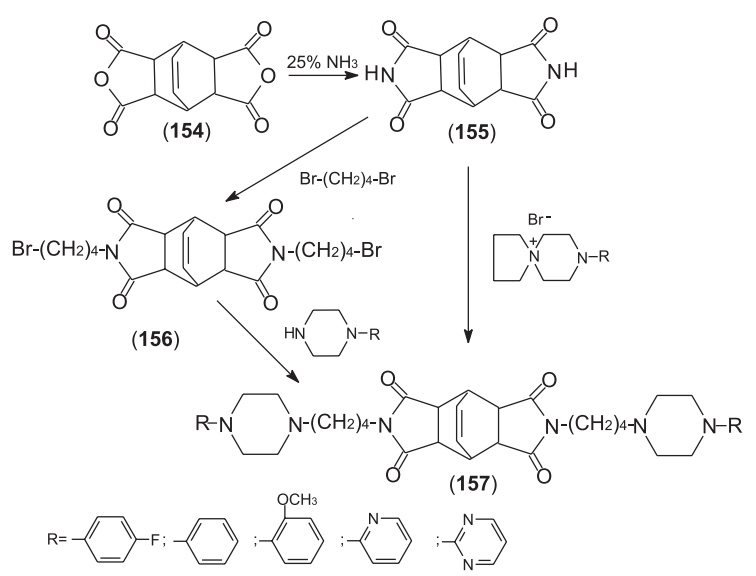

Esquema 28.

ção nos últimos anos e suas atividades biológicas, tais como antitumoral, antiviral, antibacteriana e fungicida, têm sido relatadas ${ }^{97}$. Copolímeros do tipo poli (GMI-co-MA) (GMI-N-glicinilmaleimida, e MA - ácido metacrílico) (160) e poli (GMI-co-Vac) (Vac, acetato de vinila) (161) apresentaram atividade antitumoral in vivo ${ }^{89}$.
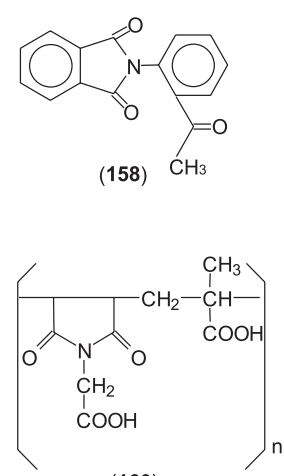

(160)
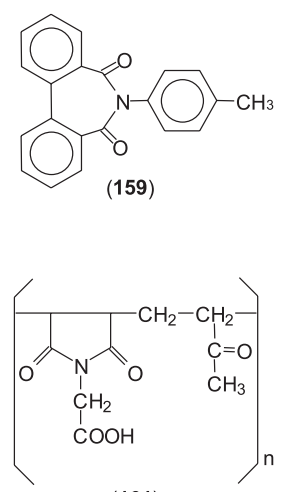

(161)
Alquil éteres, tioéteres, sulfóxidos e sulfonas derivados de succinimidas cíclicas possuem potente atividade hipolipidêmica em doses de 10 e $20 \mathrm{mg} / \mathrm{Kg}$ em roedores ${ }^{58-60}$. Foi ainda estabelecida uma correlação entre a estrutura química dos compostos e a atividade biológica aferida, bem como mostrado o efeito causado pelas imidas cíclicas na absorção de lipídios do intestino de roedores ${ }^{58-60}$.

Estudos recentes têm demonstrado que algumas imidas cíclicas são úteis para a obtenção de fármacos com liberação controlada, permitindo adequar as propriedades farmacocinéticas destes fármacos ${ }^{98}$.

\section{CONCLUSÕES E PERSPECTIVAS}

As imidas cíclicas, que compreendem várias sub-classes, como as maleimidas, succinimidas, glutarimidas, naftalimidas, ftalimidas, entre outras, apresentam promissoras propriedades medicinais. Algumas destas substâncias já se encontram em uso na terapêutica e outras emergem como possíveis candidatas a novos fármacos. Entre os principais efeitos biológicos constatados incluem-se, principalmente, os efeitos antimicrobiano, analgésico, anticonvulsivante e anticâncer, entre outros. Uma das fortes razões para o progresso e continuidade dos estudos químicos e biológicos das imídas cíclicas consiste na facilidade de obtenção, com bons rendimentos e rotas sintéticas exequíveis.
As imidas cíclicas são raramente encontradas na natureza, porém o isolamento e identificação do alcalóide filantimida (2) de origem vegetal propiciou ao nosso grupo de pesquisa a descoberta de muitos análogos sintéticos com potencial terapêutico ${ }^{4,15}$.

Face à necessidade de novos fármacos para o tratamento das mais variadas patologias, as imidas cíclicas aparecem como prováveis líderes para o desenvolvimento de novos e eficientes fármacos. No entanto, muito há de se progredir, principalmente em relação à eficácia destes compostos em estudos clínicos e à determinação inequívoca do perfil toxicológico, bem como a necessidade de elucidação dos mecanismos moleculares de ação envolvidos nas ações biológicas aqui mencionadas.

\section{AGRADECIMENTOS}

Os autores agradecem aos órgãos de fomento que deram suporte aos estudos desenvolvidos com as imidas mencionadas neste artigo (CNPq, CAPES, FUNCITEC-SC), ao CCS e à ProPPEx/ UNIVALI, ao Departamento de Química da UFSC e a todos os pesquisadores, colegas que trabalharam com as imidas cíclicas em vários artigos citados do grupo de pesquisa (Prof ${ }^{\mathrm{a}}$. S. Zacchino, Prof ${ }^{\mathrm{a}}$. E. O. Lima, Prof $^{a}$. M. M. de Souza, Prof ${ }^{\circ}$. A. B. Cruz, Prof ${ }^{a}$. R. B. Cruz, etc.).

\section{REFERÊNCIAS}

1. Barreiro, E.; Quim. Nova 1991, 14, 179.

2. Ugaz, O. L.; Investigación Fitoquímica, $2^{\mathrm{a}}$ ed., Pontificia Universidade Católica de Peru, Fondo Editorial: Lima, 1994.

3. Lozoya, X.; Investigación y Ciência 1997, Nov., 4.

4. Cechinel Filho, V.; Yunes, R. A.; Quim. Nova 1998, 2, 99.

5. Pandey, R. C.; Med. Res. Rev. 1998, 18, 333.

6. Cechinel Filho, V.; Quim. Nova 2000, 23, 680.

7. Hargreaves, M. K.; Pritchard, J. G.; Dave, H. R.; Chem. Rev. 1970, 70, 439.

8. Randall, T.; JAMA 1990, 263, 1474.

9. Singhal, S.; Mehta, J.; Desikan, R.; Ayers, D.; Roberson, P.; Eddlemon, P.; Munshi, N.; Anaissie, E.; Wilson, C.; Dhodapkar, M.; Zeldis, J.; Barlogie, B.; Siegel, D.; Crowley, J.; N. Engl. J. Med. 1999, 341, 1565.

10. Porter, S. R.; Jorge Jr., J.; Oral Oncol. 2002, 38, 527.

11. Lima, L. M.; Fraga, C. L. M.; Barreiro, E. J.; Quim. Nova 2001, 24, 683.

12. Tempesta, M. S.; Corley, D. G.; Beutler, J. A.; Metral, C. J.; Yunes, R. A.; Giacomozzi, C. A.; Calixto, J. B.; J. Nat. Prod. 1988, 3, 617.

13. Cechinel Filho, V.; Bella Cruz, A.; Moretto, E.; Pinheiro, T.; Nunes, R. J.; Yunes, R. A.; Il Farmaco 1994, 49, 675.

14. Calixto, J. B.; Yunes, R. A.; Neto, A. S. O.; Valle, R. M. R.; Rae, G. A.; Braz. J. Med. Biol. Res. 1984, 17, 313.

15. Cechinel Filho, V.; Tese de Doutorado, Universidade Federal de Santa Catarina, Brasil, 1995.

16. Andricopulo, A. D.; Cechinel Filho, V.; Santos, A. R. S.; Yunes, R. A.; Nunes; R. J.; Resumos da 20a Reunião Anual da Sociedade Brasileira de Química, Poços de Caldas, Brasil, 1997.

17. Cava, M. P.; Deana, A. A.; Muth, K.; Mitchell, A. J.; Organic Synthesis Coll. 1973, 5, 944.

18. Nunes, R.J.; Tese de Doutorado, The Hatfield Polytechnic: England, 1986.

19. Cremlyn, R.J.; Swinbourne, F. J.; Fitzgerald, P.; Godfrey, N.; Hedges, P.; Lapthorne, J.; Mizon, C.; Indian J. Chem., Sect. B: Org. Chem. Incl. Med. Chem. 1984, 23, 962.

20. Cechinel Filho, V.;Nunes, R. J.; Calixto, J. B.; Yunes, R. A.; Pharm. Sci. 1995, $1,399$.

21. Corrêa, R.; Rosa, P. W.; Bella Cruz, A.; Savi, A. O. S.; Cechinel Filho, V.; Nunes, R. J.; Pharm. Sci. 1996, 2, 353.

22. Corrêa, R.; Cechinel Filho, V.; Schlemper, V.; Rosa, P. W.; Pereira, C. I.; Nunes, R. J.; Pharm. Sci. 1997, 3, 1.

23. Barn, D. R.; Morphy, J. R.; J. Comb. Chem. 1999, 1, 151.

24. Cremlyn, R.J.; Swinbourne, F. J.; Nunes, R. J.; Quim. Nova 1985, 7, 118

25. Cremlyn, R. J.; Nunes, R. J.; Phosphorus and Sulfur 1987, 31, 245.

26. Corrêa, R.; Dissertação de Mestrado, Universidade Federal de Santa Catarina, Brasil, 1997.

27. Faul, M. M.; Winnneroski, L. L.; Krumrich, C. A.; Tettrahedron Lett. 1999, 40, 1109.

28. Cremlyn, R. J.; Swinbourne, F. J.; Nunes, R. J.; Phosphorus and Sulfur 1987, 30, 65 . 
29. Beyer, U.; Schumacher, P.; Unger, C.; Frahm, A.W.; Kratz, F.; Pharmazie 1997, 52, 480 .

30. Krajewsji, D.;Toth, G.; Schreirer, P.; Phytochemistry 1996, 43, 141.

31. Lima, E. O.; Queiroz, E. F.; Andricopulo, A. D.; Nunes, R. J.; Yunes, R. A.; Corrêa, R.; Cechinel Filho, V.; Bol. Soc. Chil. Quim. 1999, 44, 185.

32. Cechinel Filho, V.; Pinheiro, T.; Nunes, R. J.; Yunes, R. A.; Queiroz, E.; Lima, E. O.; Quim. Nova 1996, 19, 590.

33. Korolkovas, A.; Burckhalter, J.H.; Química Farmacêutica, Guanabara Koogan: Rio de Janeiro, 1988.

34. López, S. N.; Cortés, J. C. G.; Corrêa, R.; Sortino, M. A.; Corrêa, B.; Paszuck, H. C.; Cechinel Filho, V.; Ribas, J. C.; Zacchino, S. A.; 22 $2^{\text {nd }}$ IUPAC International Symposium on the Chemistry of Natural Products, São Carlos, Brasil, 2000.

35. Cechinel Filho, V.; Vaz, Z.; Nunes, R. J.; Calixto, J. B.; Yunes, R. A.; Pharm. Sci. 1996, 2, 199.

36. Cechinel Filho, V.; Corrêa, R.; Vaz, Z.; Calixto, J. B.; Nunes, R. J.; Pinheiro, T.; Andricopulo, A. D.; Yunes, R. A.; Il Farmaco 1998, 53, 55.

37. Campos, F.; Corrêa, R.; Souza, M. M.; Yunes, R. A.; Nunes, R. J.; Cechinel Filho, V.; Resumos da $23^{a}$ Reunião Anual da Sociedade Brasileira de Química, Poços de Caldas, Brasil, 2000.

38. Campos, F.; Corrêa, R.; Souza, M. M.; Yunes, R. A.; Nunes, R. J.; Cechinel Filho, V.; Arzneim - Forsch./Drug Res. 2002, 52, 455.

39. Andricopulo, A. D.; Filho, A. W.; Corrêa, R.; Santos, .A R. S.; Nunes, R. J.; Yunes, R. A.; Cechinel Filho, V.; Pharmazie 1998, 53, 493.

40. Bella Cruz, A.; Bella Cruz, R. C.; Cechinel Filho, V.; Junior, D. A.; Nunes, R. J.; Yunes, R. A; Rev. Latinoamer. Quim. 1996, 25, 10.

41. Andricopulo, A. D.; Savi, A. O. S; Corrêa, R.; Cruz, A. B.; Cechinel Filho, V.; Yunes, R. A.; Nunes, R. J.; Quim. Nova 1998, 21, 573.

42. Corrêa, R.; Rosa, P. W.; Cechinel Filho, V.; Schlemper, V.; Andriplopulo, A. D.; Nunes, R. J.; Pereira, C. I.; Alcance (Pesquisa) 1998, 3, 19.

43. Sharpless, N. E.; Flavin, M.; Biochemistry 1966, 5, 2963.

44. Lange, J.; Rump, S.; Ilczuk, I.; Lapszewicz, J.; Rabsztyn, T.; Walczyna, K.; Pharmazie 1977, 32, 579.

45. Cremlyn, R.J.; Swinbourne, F. J.; Shode, O. O.; J. Chin. Chem. Soc. 1984, 31, 383.

46. Ashraf, S. A.; Hill, J.; M'Hamedi, A.; Zerizer, H.; Tetrahedron 1992, 48, 6747.

47. Meise, W.; Al-Ashmawi, M. I.; Kull, M. A.; Boll. Chim. Farmaceutico 1996, 135, 429.

48. Obniska, J.; Zejec, A.; Karolak-Wojciechowska, J.; Il Farmaco 1999, 54, 423.

49. Lange, J.; Kázmierski, W.; Daroszewski, J.; Pol. J. Pharmacol. Pharm. 1991, 43, 71 .

50. Pavlov, S.; Bogavac, M.; Arsenijevic, L.; Arsenijevic, V.; Pharmazie 1990, 45, 286.

51. DiPardo, R. M.; Patane, M. A.; Newton, R. C.; Price, R.; Broten, T. P.; Chang, R. S. L.; Ranson, R. W.; Di Salvo, J.; Freidinger, R. M.; Bioorg. Med. Chem. Lett. 2001, 11, 1959.

52. Caswell, L. R.; Guevara, M.; Corley, L. D.; Martinez, A.V.; Hollis, T.; Largers, K.; Thornley, D. L.; Synthesis 1992, 9, 823.

53. Poupaert, J. H.; Gaetane, H.; Barbeaux, P.; Lambert, D.; Henichart, J.; Pharmacology 1995, 47, 89.

54. Vogel, A. I.; Química Orgânica, $2^{\text {a }}$ ed., Ao Livro Técnico: Rio de Janeiro, 1987.

55. Bogdal, D.; Pielichowski, J.; Boron, A.; Synlett 1996, 9, 873.

56. Antunes, R.; Batista, H.; Srivastra, R. M.; Thomas, G.; Araujo, C. C; Bioorg. Med. Chem. Lett. 1998, 8, 3071.

57. Kamal, A.; Laxman, E.; Rao, N. V.; Tetrahedron Lett. 1998, 39, 8733.

58. Chapman, J. M.; Sowell, J. W.; Abdalla, G.; Hall, I. H; J. Pharm. Sci. 1989, $78,903$.

59. Chapman, J. M.; De Lucy, P.; Wong, O.; Hall, I. H.; Lipids 1990, 25, 391.

60. Hall, I. H.; Patrick, M. A.; Maguire, J. H.; Arch. Pharmacol. Res. 1990, $323,579$.

61. Hall, I. H.; Scoville, J. P.; Reynolds, D. J.; Simlot, R.; Duncam, P.; Life Sci. 1990, 46, 1923.
62. Miyachi, H.; Azuma, A.; Ogasawa, A.; Uchimura, E.; Watanabe, N.; Kobayashi, Y.; Kato, F.; Kato, M.; Hashimoto, Y.; J. Med. Chem. 1997, $40,2858$.

63. Bousvaros, A.; Mueller, B.; Drugs 2001, 61, 776.

64. Hashimoto, Y.; Bioorg. Med. Chem. 2002, 10, 461.

65. Ribeiro, R. A.; Vale, M. L.; Ferreira, S. H.; Cunha, F. Q.; Eur. J. Pharmacol. 2000, 391, 97.

66. Komoda, M.; Kakuta, H.; Takahashi, H.; Fujimoto, Y.; Kadoya, S.; Kato, F.; Hashimoto, Y.; Bioorg. Med. Chem. 2001, 9, 121.

67. Konstantinova, T. N.; Meallier, P.; Grabchev, I.; Dyes Pigm. 1993, 22, 191.

68. Grabchev, I.; Meallier, P.; Konstantinova, T. N.; Popova, M.; Dyes Pigm. 1995, 22,191.

69. Grabchev, I.; Konstantinova, T. N.; Dyes Pigm. 1997, $28,41$.

70. Grabchev, I.; Philipova, T.; Indian J. Chem., Sect. B: Org. Chem. Incl. Med. Chem. 1997, 36, 264.

71. Torres Suárez, A. I.; Camacho, M. A.; Arzneim.-Forsch. 1994, 44, 81.

72. Asbury, R. F.; Blessing, J. A.; Soper, J. T.; Am. J. Clin. Oncol. 1994, 17, 125.

73. Reynolds, D. J.; Wong, O. T.; Simlot, R.; Chang, J. J.; Hall, I. H.; Arch. Pharm. (Weinheim) 1994, 327, 237.

74. Braña, M. F.; Castellano, J. M.; Morán, M.; Emling, F.; Kluge, M.; Schlick, E.; Klebe, G.; Walker, N.; Arzneim. Forsch. 1995, 45, 1311.

75. Cani, G. S.; Müller, L. A.; Monografia de Conclusão de Curso (Farmácia), Universidade de Vale do Itajaí, Brasil, 1999.

76. Andricopulo, A. D.; Müller, L. A.; Cechinel Filho, V.; Cani, G. S.; Ross, J. F.; Corrêa, R.; Santos, A. R. S.; Nunes, R. J.; Yunes, R. A.; Il Farmaco 2000, 55, 319 .

77. López, S. N.; Sortino, M.; Escalante, A.; Campos, F.; Corrêa, R.; Cechinel Filho, V.; Nunes, R. J.; Zacchino, S.A.; Drug Res. 2003, in press.

78. Dounchis, H.; Volpp, G. P.; J. Med. Chem. 1971, 14, 241.

79. De, A. U.; Pal, D.; J. Pharm. Sci. 1975, 64, 264.

80. Winnik, M. A. ; Chem. Rev. 1981, 81, 491.

81. Baldwin, J. E.; J. C. S. Chem. Comm. 1976, 734

82. Stiz, D. S.; Souza, M. M.; Golim, V.; Netto, R. A. E.; Corrêa, R.; Nunes, R. J.; Yunes, R. A.; Cechinel Filho, V.; Pharmazie 2000, 55, 12.

83. Patel, V. K.; Bhatt, H. V.; Patel, N. B.; Jindal, M. N.; Biomed. Biochim. Acta 1985, 44, 795.

84. Goehring, R. R.; Greenwood, T. D.; Nwokogn, G. C.; Pisipati, J. S.; Rogers, T. G.; Wolfe, J. F.; J. Med. Chem. 1990, 33, 926.

85. Aboagye, F. A.; Sam, G. H.; Massiot, G.; Lavaud, C.; Fitoterapia 2000, 71,461 .

86. Nicholson, G. M.; Spence, I.; Johnston, G. A. R.; Neuropharmacology 1995, 24, 461 .

87. Riblet, L. A.; Taylor, D. P.; Eison, M. S.; Stantan, H. C.; J. Clin. Psychiatry 1982, 42, 11

88. Yebich, J. P.; New, J. S.; Smith, D. W.; Lobeck, W. G.; Catt, J. D.; Minielli, J. L.; Eison, M. S.; Taylor, D. P.; Riblet, L. A.; Temple, D. L.; J. Med. Chem. 1986, 29, 359.

89. Zawadowski, T.; Kossakowski, J.; Rump, S.; Jakowicz, I.; Plaznik, A.; Acta Pol. Pharm.-Drug Res. 1995, 52, 43.

90. Kossakowski, J.; Jarocka, M.; Farmaco 2001, 56, 785.

91. Michalska, D.; Morzys, B.; Bienko, D. C.; Wojciechowski, W.; Med. Hypotheses 2000, 54, 472.

92. Fujinami, A.; Ozaki, T.; Yamamoto, S.; Agr. Biol. Chem. 1971, 35, 1707.

93. Aboul-Enein, H. Y.; Org. Prep. Proced. Int. 1975, 7,14.

94. New, J. S.; Yevich, J. P.; Temple, O. L.; New, K. B. ; Gross, S. M.; Schlemmer, R. F.; Eison, M. S.; Duncan, P. T.; Riblet, L. A.; J. Med. Chem. 1988, 31,618 .

95. Turto, J.; Zawadowski, T.; Rumpo, S.; Jakowicz, I.; Gidynska, T.; Gatecka, E.; Pol. J. Pharmacol. 1994, 46, 451.

96. Turto, J.; Zawadowski, T.; Il Farmaco 1996, 51, 815.

97. Gam, G. T.; Jeong, J. G.; Lee, N. J.; Lee, Y. W.; Há, C. S.; Cho, W. J.; J. Appl. Polym. Sci. 1995, 57, 219.

98. Matsumoto, H.; Sohma, Y.; Kimura, T.; Hayashi, Y.; Kiso, Y.; Bioorg. Med. Chem. Lett. 2001, 11, 605. 